\title{
Theoretical construction of sustainable social awareness in mexican organizations
}

\section{La construcción teórica de la conciencia social sustentable en las organizaciones mexicanas}

OJEDA-GUTIÉRREZ, Maricela†*’’, MARTÍNEZ-TORRES, Rosa Elia” and RIVERA-ACOSTA, Patricia"

'Universidad Politécnica de San Luis Potosí, Mexico.

"Tecnológico Nacional de México / Instituto Tecnológico de San Luis Potosí, Mexico.

ID $1^{\text {st }}$ Author: Maricela, Ojeda-Gutiérrez / ORC ID: 0000-0002-4655-2391, CVU CONACYT ID: 740613

ID $1{ }^{\text {st }}$ Co-author: Rosa Elia, Martínez-Torres / ORC ID: 0000-0001-8936-9207, CVU CONACYT ID: 953355

ID $2^{\text {nd }}$ Co-author: Patricia, Rivera-Acosta / ORC ID: 0000-0002-8254-0005, CVU CONACYT ID: 232611

DOI: $10.35429 / E J R N .2021 .13 .7 .10 .20$

Received July 15, 2021; Accepted December 30, 2021

\begin{abstract}
This article gives an account of the qualitative research process under the Grounded Theory strategy to generate a substantive theoretical construct called Sustainable Social Culture from instrumental records product of an immersion in the field in four industrial units (Martínez, 2020). The first findings raised questions that led to delving into the way in which industrial workers exercise agency and reflexivity in terms of sustainability. This theoretical construct rests on the Sociology of Organizations, Organizational Culture and Environmental Management that contribute to integrating categorical dimensions for their subsequent theorization and conceptual integration whose consistency, internal logic and validity are evidenced.
\end{abstract}

Sustainable Social Awareness, Environmental Management Culture, Agency, and Reflexivity

\begin{abstract}
Resumen
Este artículo da cuenta del proceso de investigación cualitativa bajo la estrategia de Teoría Fundamentada para generar un constructo teórico sustantivo denominado Cultura Social Sustentable a partir de registros instrumentales producto de una inmersión al campo en cuatro unidades industriales (Martínez, 2020). Los primeros hallazgos motivaron interrogantes que llevaron a profundizar sobre la manera en que los trabajadores industriales ejercen capacidad de agencia y reflexividad en términos de sustentabilidad. Este constructo teórico descansa en la Sociología de las Organizaciones, la Cultura Organizacional y de Gestión Ambiental que contribuyen a integrar dimensiones categoriales para su posterior teorización e integración conceptual cuya consistencia, lógica interna y validez se evidencian.
\end{abstract}

Conciencia Social Sustentable, Cultura de Gestión Ambiental, Agencia y Reflexividad

Citation: OJEDA-GUTIÉRREZ, Maricela, MARTÍNEZ-TORRES, Rosa Elia and RIVERA-ACOSTA, Patricia. Theoretical construction of sustainable social awareness in mexican organizations. ECORFAN Journal-Republic of Nicaragua. 2021. 7 13:10-20.

\footnotetext{
* Correspondence to Author (Email: maricela.ojeda@upslp.edu.mx)

$\dagger$ Researcher contributing first author.
} 


\section{Introduction}

The World Commission for the Environment and Development (1987) defines sustainability as the one that promotes both the fulfillment of current needs, and the guarantee for the good use of resources for the future generations. To achieve this task, social organizations and institutions must become aware of the problems that humanity faces in environmental terms to seek strategies in scientific and technological contributions, and with it, move towards a new organizational culture that is sustainable. However, this persistence embodied in the 2030 Agenda for the management of public policies in favor of the sustainability, as well as its execution guidelines have not reached yet the requirements needed to positively impact the organizational culture of economic units of the industrial sector.

On the other hand, a constant restructuration is perceived in some branches of the industrial category in two senses: by the regulations of all kinds that require changes in processes, procedures as well as in the behavior of workers, and by technological changes that require better practices. Some examples can be found in the mining-metallurgical industry, where it is observed that since the last decade of the last century, it has been gradually adjusting its organizational and procedural strategies to meet the international and national regulations, whose central approach is focused on Sustainable Development.

A specific case was the result of the application of a Management Model for Sustainability (Martínez, 2020) whose main goal was to establish the level of compliance with the current legislation known as the Environmental Impact Manifesto-EIM-(SEMARNAT, 2020) and the alignment with the environmental objectives of the 2030 Agenda that were managed by four mining units located in centralnorth, central-south and a Ag-Au-Zn-Pb mineralization trend of the Mexican Republic. During the three years of immersion in these units, different data collection instruments were applied, and their results generated new question related to Organizational Culture, opening a gap of opportunities to deepen them.
When analyzing the Organizational Culture of these units, a significant discrepancy was found among the management priorities established as a strategic plan by the senior management as opposed to the daily work carried out by middle managers and operator in terms of sustainability. It was an unexpected finding in the research carried out in the field, which highlights that some mining workers, although they demonstrate knowledge regarding the functions, obligations and tasks established by the management and these are consistent, in most cases, towards the sustainability, its environmental reflexivity is not clearly expressed when carrying out its work.

The sociological notion of reflexivity (Giddens, 2006) takes a preponderant role in this study due to the recognition of the conceptual transition in favor of the environment that is occurring in many industries in general and has had an important impact also in the mining sector particularly. The agency capacity is perceived from the environmental reflexivity on the impact of actions in past, present and future events, which directly affects the decisions that individuals must consciously transform the environment in which they participate at work. Nonetheless, the scope of the study carried out between 2018 and 2020 did not consider a specifically designed way to evaluate the levels of awareness towards sustainability that workers in this sector managed.

This led to create new questions: first, about the meaning that workers give to environmental management and the environmental impact of their industrial actions; second, about the recognition of the impact that their actions have on the environment; third, about the degree of choice that worker have regarding their work in environmental matters.

These questions guided the research path towards the field of organizational sociology as a basic theory that allows to inquire into what is called Environmental Management Culture, to determine the degree to which industrial workers have appropriated the sustainability in their work actions. 
Hence, the general objective of this research is to explain the conformation of the Sustainable Social Awareness that industrial workers handle based on four sustainable principles that the 2030 Agenda handles and that are aligned with the current legislation in Mexico on environmental matters. Understanding that Sustainable Social Awareness is one of the necessary indicators to understand more precisely the Environmental Management Culture that is occurring in industrial environments.

Taking as the hypothesis that, as part of the Environmental Management Culture within companies, workers consolidate a Sustainable Social Awareness based on the meaning they give to the environmental management and that their industrial practice corresponds to the degree of choice they have on the impact of their actions.

Once the reasons that have led us to delve into the meanings and sustainable industrial practices of industrial workers are defined, this document is organized in five fundamental parts: the first gives an account of the theoretical principles that support the theoretical construct of Grounded Theory. Second, it will be possible to find the methodological design to give way to the third and fourth part of the document that discusses the results of the axial, open and selective codes, which contribute to the substantive theoretical construct of Sustainable Social Awareness. This document ends with some reflections and bibliographic references as sections five and six, respectively.

\section{Theoretical bases}

To answer the initial questions, a literature review was essential to identify an opportunity gap in the preliminary findings obtained through a field immersion. In the following sections, some of the postulates on the Sociology of Organizations, Organizational Culture, Environmental Management, Agency capacity and reflexivity are briefly exposed.

\section{Sociology of organizations}

From the perspective of the Sociology of Organizations, this document adheres to the conceptual definition with the greatest scientific acceptance that indicates that organizations are complex social systems, independent and interrelated with other systems.
From the complexity, the sociological explanation is that it is about open and closed organizational systems insofar as they are concerned with relationships both within the organization and in its environment, where there are adjustments and adaptations that affect the way in which it is carried out, in regards of technology, structure, process, efficiency, among other things (Scott, 2005).

Although the sociology of organizations contemplates elements of evolution in organizational models, the approach that is desired to be highlighted is its role for the understanding of individuals withing companies. As some authors point out, "individuality versus structure" (Lucas, García \& Llano, 2014); this individuality is highlighted to show their role and how their influence transforms workspaces due to the knowledge applied in technology, science, and innovation at the service of production, but also due to changing beliefs, ideologies and meanings about work and its role within organizations, especially when it comes to issues related to Sustainability.

Therefore, the focus of interest of the sociology of organizations is centered on studying the structures, processes, conflicts, and meanings that occur within the context of industrial organizations, on one side, but also considering the social processes that occur within them. The aim of organizational sociology is to obtain a more complete vision of organizational life through a more global explanation of both the problems and the opportunities for action that arise in this industrial context. Lucas, García and Llano (2014) argue that within organizations there are contradictions between daily tasks and official norms, and these deviations mean problems worth studying, such as the case at hand.

It is certain that organizations - factories, companies - are complex and changing systems by their very nature, but also by the influence of other systems with which they interact. However, it is possible to observe in its sociological analysis some variables that are maintained over time in terms of their description but not in their involvement in industrial processes. Such analytical variables worth mentioning have been exposed in the sociological literature (Tilly, 2001; Scott, 2005) regularly: 
Actors: are people who play several roles within organizations, its analysis is directed to their cooperation in the workplace; some topics of sociological interest are related to identity, beliefs, and symbolic configurations, among others.

Relationships: they are about human interaction, and its analysis goes in the sense of communication patterns and networks, teamwork, and even labor conflicts, among other topics.

Activities: related to the functions that are carried out, the daily tasks and obligations or in specific situations; its analysis is directly related to the effectiveness, efficiency, productivity and profitability of companies.

Legal and regulatory criteria: the aspects of property, contracts, control rights, and regulatory applications are addressed; its analysis is on the border of the "should be" of the companies and their members.

However, there are other analytic variables that seem to emerge and consolidate as a fertile field for its sociological study, from which the conception of the organization as a relational system stands out. According to Scott (2005), there is a growing number of sociological studies that adopt the relational approach because they start from the premise that organizations are inseparable from the transactional contexts in which they are embedded and that they derive their meaning and identity from the roles they play in these encounters. This author points out that the relational sociological approach is carried out on the organizational structure that is continuously being "created and recreated" since the actors are "constructing and reconstructing" the intentions in descriptions and, therefore, their own identities and those of others (Scott, 2001). It is from this sociological perspective that this research is supported to verify the ideological changes that are occurring in the Mexican mining-metallurgical industry referring to its environmental practices; that is why it is an emerging sociological focus, it has theoretical and methodological relevance.

\section{Organizational Culture}

Most authors (Chiavenato, 2007; Robbins and Judge, 2013) agree by pointing out that from the moment an individual joins an organization, they become part of it and, therefore, will have to assimilate its culture. It is a daily interaction where prevailing attitudes, underlying presuppositions, aspirations, and relevant issues are part of the organization's culture.

According to Robbins and Judge, (2013), organizational culture is characterized by: establishing differences between one organization and another as it helps define borders; transmit the feeling of identity among the members; generate collective commitment; increase the stability of the social system through unity; serve as a mechanism that gives meaning and control, that guides and shapes the attitudes and behavior of employees.

In favor of perpetuating the organizational culture, many organizations seek that their members, that is, their workers, possess values essentially consistent with the values proclaimed by each company, hence, from the selection, hiring, permanence to the promotion of their personnel, they are influenced by decision makers. Another factor to maintain the organizational culture is the effect that the top management prints as norms that filter through the organization whose manifestations range from the ideology about work and its social, economic, and in our case, environmental repercussions, to the establishment of objectives, goals and strategies, benefit systems, uniforms, among other things. The third and last factor is socialization, understanding this as the formation of social networks whose influence is directly related to what is considered accepted or rejected in terms of socio-labor practices, generating a sort of "metamorphosis" in each worker who will inevitably align themselves to the prevailing organizational culture (Robbins and Judge, 2013).

The literature specialized on the subject indicates that the organizational culture is intangible, deep, and rooted in people, however it is possible to measure its effects and consequences once the different strata in which it is composed are known. Chiavenato (2007) compares it with an iceberg to provide an explanation of the different strata that compose it: 
Superficial stratum: built of physical and concrete formal aspects such as organizational structure, jobs, organizational objectives, strategies, technology, organizational practices, personnel policies and guidelines, work methods and procedures, productivity, and financial measures.

Deep stratum: made up of informal aspects, whose invisible, hidden, affective, emotional components are oriented towards the social and psychological aspects of its members, such as patterns of influence and power, perceptions and attitudes of people, feelings, and group norms, values and expectations, patterns and formal interactions and affective relationships (Chiavenato, 2007: 85).

Following Luthans (2002) of the most significant components of the organization culture are:

a. Regularity in the observed behaviors: characterized by the fact that its participants have a common language, their own vocabulary, and rituals related to behaviors.

b. Norms: whose behavior patterns include guidelines for doing things.

c. Predominant values: shared form top management and permeated through the behavior of its members.

d. Philosophy: through policies that reinforce beliefs about aspects related to processes and dealing with people.

e. Rules: understood as the established guidelines and related to behavior within the organization.

f. Organizational climate: as the feeling transmitted by the work environment on which the interaction, treatment of others, attention to clients and suppliers, among other things, intervene (Luthans, 2002).

\section{Environmental Management}

Adding to the global scientific consensus, environmental management is the set of actions and strategies aimed at organizing activities that influence the environment, thereby obtaining life quality and warnings to problems in the environment to protect the environment.
It is recognized in this construct the existence of dimensions and factors that intervene to achieve or stop the adequate balance between economic and population growth on one side and the rational use of resources and the protection and conservation of the environment.

Talking about Environmental Management refers us to a broad context of international relations and international cooperation programs whose impulse and insistence on creating regulations in favor of the environment is transferred to governments, institutions, organizations and, to a lesser extent, to people around the world. Especially in the Latin American and Caribbean region where a diversity of territories, populations, economies, ecosystems, and visions coexist to address critical environmental issues.

The roots of Environmental Management have their foundations from the United Nations Conference on Human Environment and the United Nations Conference on Environment and Development (UNCED, 1972, 1987 and 1992) from which a renewed vision towards the conservation and rational use of resources that persist to this day and consequently a higher priority in the state agendas that would put into operation national legislation and policies focused on the environment (Rodríguez-Becerra and Espinoza, 2002).

Multilateral agreements between neighboring countries to protect ecosystems were immediate, as the slogan was clear: to improve environmental quality through determined management. However, the world would see an accelerated deterioration in natural resources and the environment, evident in deforestation, desertification, and the pollution of the oceans (Rodríguez-Becerra and Espinoza, 2002). The result: a new international call to establish the World Commission on Environment and Development (WCED, 1987) from which the term Sustainable Development arises, understood as a goal of the highest political level to which all nations should address to alleviate said environmental deterioration of the last few years. 
Particularly in Latin America, the Ecobíos International Conference (CDMAALC, 1990) would establish its own agenda to achieve Sustainable Development, whose proposal focuses on economic growth, social justice and the environment and implies social cohesion, the recognition that natural resources are limited and that the environmental capacity must also include waste management (UN, 1993).

To achieve this effort, 17 Sustainable Development Goals, described in the 2030 Agenda, are established, and the achievement of which implies determined and specific actions; that is, an operation to obtain financing for remediation in case of environmental impact, the inclusion of human habits in favor of the environment, the creation of services and opportunities, as well as more efficient production and operation processes (Naredo, 1996).

In order to reach this goal, strategic planning refers us to Sustainability, which refers to the regulation of public and social policies to use natural resources more efficiently in order to satisfy the current needs of human beings, but without compromising the resources of future generations (Naredo, 1999).

The Sustainable Environmental Management is, for this research work, the set of strategies and operational methods to effectively carry out concrete actions to use natural resources to achieve a profitable and beneficial position in environmental terms in the short, medium, and long term. This definition permeates the Organizational Culture described in previous paragraphs due to its direct interference in the industrial organizations that are the discussion of this study.

\section{Agency capacity and reflexivity}

With the plan of explaining from sociology the way in which individuals are conformed as social and historically conformed beings, it is necessary to refer to two emerging concepts: human agency and reflexivity. Both concepts are theoretically supported by the proposal of Giddens (2006) who explains that within the constitution of society, the human being is part of an interrelation between the social structure that gives cohesion and belonging to a group or community; and it is in this interrelation that both the social structure affects the decisions and actions of the individual and vice versa.
Giddens (2006) establishes that human action is a competence that each person has in order to do things and, therefore, the ability to influence the behaviors of other actors. As part of these competencies, the ability to transform circumstances and contexts becomes crucial. Giddens defines this phenomenon of action as human agency and the individual becomes an agent that acts, influences, and allows the influence of other people, other events within the social structures to which the person belongs.

But human agency is not complete without the second concept: reflexivity, that encompasses both the awareness of social actions and the awareness of the practice of their decisions. Then, for the agent to be able to exercise a power, it must be understood that the conditions in which the agent acts, have objectives and intentions based on which the behavior can be guided, and of course, expectations in relation to others, and the results of such actions will be set.

According to this author, the social structures in which the agents are immersed and that influence their performance are the political system of the nation-state that corresponds to the geographical place where they live, the system of social reproduction that constantly exchanges new social evaluations, that leads to the reformulation of the human worldview and therefore, a transformation that configures a new social order.

For this present case, these two concepts contribute to deepen into how the Culture of Environmental Management becomes a reference that involves the agency and reflexivity capacity as means to transform industrial spaces in favor of the environment. 


\section{Methodological design}

Within the wide range of qualitative research methods that exist to explain the conformation of Sustainable Social Awareness that workers handle because of their Agency capacity and reflexivity in terms of Environmental Management, the Grounded Theory has been chosen, as the ideal qualitative research method. Following Creswell (2005), Strauss and Corbin (2002), the Grounded Theory provides a broader, deeper, and more comprehensive sense of understanding, since it allows the representation of the complexity of a phenomenon paying attention to the social processes that take place in natural environments, avoiding preconceived conceptual frameworks. So far, it has been found that the specialized literature on Sociology of Organizations, Organizational Culture and Environmental Management, cannot fully explain the phenomenon that has been identified as a study problem for this research, hence, this methodological selection.

Therefore, the research design that was carried out to answer the research question is through Grounded Theory of a systematic type (Creswell, 2005; Strauss and Corbin, 2002), understanding that it is the search for a substantive theory that adheres to the formal theory of Environmental Management as a scientific contribution by:

- $\quad$ Paying attention to what people say and do, avoiding stereotypical ways of thinking about the phenomenon.

- Focusing on the data without taking anything for granted by stimulating the inductive process.

- Formulating interim questions and answers that lead to categories with innovative properties and dimensions.

Offering alternative meanings to the phenomena.

Observing the obtention of a substantive theoretical construct, this research design allows the conceptual ordering and its subsequent theorization through the meanings that industrial workers give to their work practice with a Sustainable Environmental Management approach. Therefore, the sample units are organized as follows:
- $\quad$ Records of the participant observation and checklists made during the employment of the Management Model for Sustainability (Martinez, 2020) in the years 2018, 2019 and 2020.

- $\quad$ Records of in-depth interviews conducted with industrial workers - managers, middle managers, and operators - during the immersion in units of the miningmetallurgical sector located in the Au-Ag$\mathrm{Pb}-\mathrm{Zn}$ metallic trend in the years 2018 , 2019 and 2020.

- $\quad$ Records of in-depth interview conducted with experts in Environmental Management in the last semester of 2020 and the first quarter of 2021.

Stage 1. Codification and classification of the findings made during the implementation of the Management Model for Sustainability (Martínez, 2020). This stage includes an analytical process called open codification to identify key concepts in participant observation records, checklists, and in-depth interviews from "in vivo codes" (Glaser and Strauss, 1967) that lead to classification and categorization in regarding relationships, properties, and dimensions.

Stage 2. Axial and selective codification that comes up from the previous stage from which the categories and subcategories were obtained as inputs to begin to formulate the first explanatory approximations about the phenomenon. This stage includes a preliminary theoretical integration process that occurs thanks to the immersion in the records of interviews with experts and their triangulation with the previous stage.

Stage 3. Formulation of the theoreticalexplanatory model where it is possible to identify the conceptual affinity that emerges from the empirical data. This stage includes the formulation of the central category that includes the conceptual idea under which all the elements of the interpretive categories generated during the previous stage will be grouped. Said conceptual integration represents an abstract expression that will have consistency, internal logic, and construct validity. 


\section{Results}

The following sections give an account of the methodological process and thereby explain the conformation of Sustainable Social Awareness as an indicator of the Environmental Management Culture that takes place in Mexican industrial organizations.

\section{Theoretical substantive Sustainable Social Awareness}

construct:

The Grounded Theory methodological strategy first led us to identify the regularities, discrepancies and relationships in the data collection records. With this first approach that goes through codification, classification, up to the exhaustive selection of primary and secondary categories, it was possible to formulate a central category that would trigger a preliminary theoretical integration.

This preliminary theoretical integration that contained some categorical dimensions favored its contrast with the sociological theories of Sociology of Organizations, Organizational Culture and Environmental Management, finding a link in general but that did not answer our initial questions to reformulate new ones.

As a result, a substantive theoretical construct called Sustainable Social Culture is obtained, that takes as its foundation the sociological contributions of structural and organizational theories to first understand that Social Consciousness is a complex term that is transformed over time as a product of circumstances of matter that occur in societies but also with ideological representations that influence individual and group actions.

According to sociology, the Social Awareness has the following features: a) It is psychic, it comes from the internal experience of a person, before the social world; b) it is immanent, it derives from an individual intern process to act in front of others; c) It is irreducible to the individual conscience, since both are implied or superimposed; d) It is intermittent, since it is exercised under certain events, by virtue of the circumstances that affect the group; and finally e) It is versatile, there are as many social consciences as unified groups (Orgaz, 2016).
However, the Social Awareness handled by industrial workers, the reason for this research, in addition to encompassing the above, adds two features that deserve attention: f) reflexivity, as the individual who realizes the social bond in which he is immersed and therefore their actions respond to: g) the agency capacity exercised as a volitional process that positively or negatively impacts the group or collective to which it belongs but also has consequences in the immediate and mediate environment where it operates.

These two characteristic featuresAgency capacity and reflexivity-are consolidated as the motor of action so that the agent consciously reacts to the stimuli of the environment that are in the order of the social pressures exerted in the society of which it is a part, but also as ideological elements of an Organizational Culture that prints values, guidelines and forms of behavior. It is in this process of social reconstruction that Social Consciousness is being configured and strengthened through the different experiences that are had on matters that are of peculiar importance at the individual, group, community, national, and even global level.

These external influences related to the conservation of the environment and the environmental impact caused by man, reflected in various documents, and disseminated through international public policies (2030 Agenda), national legislation (SEMARNAT, 2002), but also through planning strategic with a sustainable vision of different organizations that permeate through the Organizational Culture in their employees, are shaping what we call Sustainable Social Awareness.

Therefore, our substantive theoretical contribution called Sustainable Social Awareness is an active process that begins individually through observations on the impact that is exerted on the environment but is consolidated collectively when responding to actions related to the environmental impact, social responsibility, ecological aspects and commitment to future generations.

This Sustainable Social Awareness takes place in industrial spaces and arises as an ideological and participatory expression with a view to addressing the pressing environmental issue from the labor practice. 
It is sheltered by the Culture of Environmental Management generated at the highest levels of political decision, but its precepts go down until it reaches individuals through organizations that install environmental policies either due to legal pressure, or environmental conviction, resulting in staff with agency capacity who choose to act in favor of or stay out of the environment through reflexivity. Therefore, Sustainable Social Awareness becomes a qualitative indicator that directly affects the Culture of Environmental Management within Organizations.

\section{Category dimensions of Sustainable Social Awareness}

The culture of Environmental Management within organization is a complex phenomenon where elements of different nature converge. Among these, the substantive construct that we present called Sustainable Social Awareness stands out as a new vision of the world that requires certain behaviors derived from reflexivity on the impact of individual and collective actions, but also the agency's capacity to carry out strategies for preservation of resources for future generations.

It was through the Grounded Theory that some categorical dimensions were identified, that nourish Sustainable Social Awareness and that allow establishing levels and even ranges for their individual, work and professional volitional exercise for their subsequent measurement system that will be the product of a new contribution. to the field of knowledge and its practical application in industry.

Through the explanation of records related to the guidelines of the 2030 Agenda and the national regulations in force in Mexico (SEMARNAT, 2030) it was found that Sustainable Social Awareness can be ordered in the following categorical dimensions:
Dimension one: Conscience of environmental impact, related to the Sustainable Principle of Industry, Innovation and Infrastructure: it refers to the agency capacity that is reflexively exercised to identify, measure and / or mitigate the environmental impact; observation of the physical aspect of the environment; preventive-corrective maintenance to mitigate landscape damage as well as the observation and execution of international guidelines in relation to environmental policy represented by the modernization and reconversion of industries through the practical exercise of their knowledge with a Sustainable perspective and the adoption of technologies and clean processes.

Dimension two: Social responsibility awareness referred to the Sustainability principle, sustainable cities, and communities: it is recognized as the observance for the development and progress of communities surrounding the industrial center; migration control; the promotion of trades and educational resources with a sustainable vision; the promotion of access, transportation, urbanization, and protection of the cultural and natural heritage; the management of economic, social and environmental support.

Dimension three: Resource preservation awareness for future generations adhered to the Sustainable Principle of Responsible Production and Consumption: it is made up of the monitoring of operational processes that people follow within organizations; the observance of extraction systems, metallurgical processes with areas for improvement; the use on energy and water; upgrading or acquiring clean technology equipment; the management of budget items; the use of reagents; the treatment of liabilities and the calculation of reserves; the management and efficient use of natural resources and waste.

Dimension no. four: ecologic awareness linked to the Sustainability Principle: life of the terrestrial ecosystems: articulated through the reduction of degradation, devastation by extraction, deposit of liabilities; image and landscape evaluation; the observance of the parameters established in the environmental legislation (LGEEyPA, 2018) and the Environmental Impact Manifesto (MIASEMARNAT, 2002) that are evaluated and concentrated at this level. 
The following illustration is a schematic representation of the interrelation that exists among the composing dimensions of the Sustainability Social Culture.

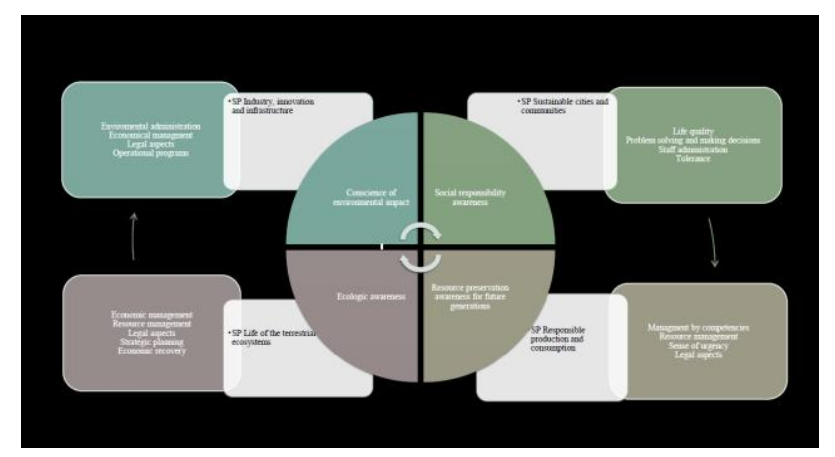

Figure 1 Configuration of category dimensions of Sustainable Social Awareness

Source: Own elaboration

As it is noted, the presented dimensions function as constituent elements of Sustainable Social Awareness that are interrelated, generating a conceptual interpretation to proceed to assess their consistency, internal logic, and construct validity, which will be the subject of a later dissemination article. During the axial coding process, it was possible to notice that there is a set of properties within each category that allow a more precise and complete explanation. These properties adhere to each dimension forming ranges of consciousness that are organized as follows:

Within development, the agency capacity is limited by the embryonic knowledge of sustainability and its application may or may not be present in the work or professional practice.

At disposition, the agent consolidates its sustainable knowledge, but there are external elements that limit its practical application in the work or professional practice.

In competences, the reflexivity impulses the agent to question the actions in favor of the environment with a sustainable vision.

In unification, the Sustainable Social Awareness is present in the agent's actions, product of reflexivity and the agency capacity, that inquires the agent's behavior and leads into sustainable actions.

\section{Final regards}

The Sustainable Social Awareness is a theoretical contribution that substantively contributes to strengthening organizational sociological theories in terms of Environmental Management Culture. This theoretical construct works to explain the way in which industrial workers are becoming aware of their role within organizations as transformation or environmental preservation agents. Its individual, social and organizational implications in terms of Sustainability emerge to make room for a new construct that can also become quantitatively operational to assess the environmental management exercised by individuals within organizations.

The present document displays how the Sustainable Social Awareness is demonstrated directly or indirectly in the daily work of worker. It then becomes an input to assess not only the knowledge in environmental matters, but also the awareness necessary to exercise agency capacity through reflection on environmental issues that require showing an implication towards the labor and professional choices that have a place in industrial organizations.

\section{References}

Chiavenato, I. (2007). Administración de recursos humanos en: El capital humano de las organizaciones. México: McGrawHill.

Comisión Mundial sobre el Medio Ambiente y el Desarrollo (1987). Nuestro Futuro Común. ONU.

DOF (2018). Ley general de equilibrio ecológico y la protección al ambiente. México.

Creswell, J. W. (2009). Research design: Qualitative, quantitative, and mixed methods approach. SAGE Publications, Inc.

Giddens, A. (2006), La constitución de la sociedad. Bases para la teoría de la estructuración. México: Amorrortu Editores.

Giddens, A. (2009), La política del cambio climático. México: Alianza.

Lucas, A., García, P., y Llano, S., (2014). Sociología de las Organizaciones. España: Editorial Fragua. 
Luthans, Fred (ed) (2002). Organizational behavior. McGraw-Hill: Nueva York.

Martínez, R. (2020). Modelo de Gestión Sustentable para la Industria Minera Metálica de México (Tesis Doctoral). Universidad de Lodz, Polonia.

Naredo, J. (1999). Sobre la "Sostenibilidad" de los sistemas en: Desarrollo económico y deterioro ecológico. pp 57-70. Colección Economía y Naturaleza. Argentina: Fundación Argentaria.

ONU (2016). Agenda 2030 y los Objetivos de Desarrollo Sostenible. Chile: Naciones Unidas.

ONU (1993). Informe de la Conferencia de las Naciones Unidas sobre el Medio Ambiente y el Desarrollo. Brasil: Naciones Unidas.

Orgaz, R., (2016). La Conciencia Social. Revista Mexicana de Sociología, 4, pp 61-74.

Robbins, S., y Judge, T., (2013). Sistemas organizacionales en Comportamiento Organizacional. México: Pearson, pp. 511-542-

Rodríguez-Becerra, M. y Espinoza, G. (2002). Gestión ambiental en América Latina y el Caribe. Washington: Banco Interamericano de Desarrollo.

Scott, W.R. (2001) Institutions and Organizations. California: Sage.

Scott, W.R., (2005). Organizaciones: características duraderas y cambiantes. Revista de Gestión y Política Pública. Volumen XIV, Número 3, pp 439-463.

Strauss, Anselm; Corbin, Juliet. (2002). Bases de la investigación cualitativa. Técnicas y procedimientos para desarrollar la teoría fundamentada (1a ed. español). SAGE Publications, Inc.

SEMARNAT, (2002). Guía para la presentación de la Manifestación de Impacto Ambiental Minero. México: SEMARNAT.

Tilly, Ch., (2001). Welcome to the seventeenth century en: The twenty-first century firm: changing economic organization in international perspective. Princeton: Princeton University Press. Pp.200-209. 